\title{
Elderly at the edge of risk in the village ecosystem
}

\author{
SANDHYA RANI AND PROMILA SHARMA
}

Received: 25.06.2015; Revised: 21.10.2015; Accepted: 30.10.2015

See end of the paper for authors' affiliations

\section{SANDHYA RANI}

Department of Family Resource

Management, College of Home

Science, G.B. Pant University of

Agriculture and Technology,

Pantnagar, U.S. NAGAR

(UTTARAKHAND) INDIA

Email : sagarsandhya13@gmail.

com
ABSTRACT : Aging is defined as a progressive deterioration of physiological functions with age. It brings about a number of physiological changes. It not only affects a person's looks, but also becomes a cause of physical deterioration. This study was undertaken to understand the health risk of elderly people and to gather some information about their perceived health needs in the village ecosystem of Udham Singh Nagar district of Uttarakhand, India. The present study is descriptive in nature. Herein, an attempt is made to describe the situation and major health problems faced by the elderly from 140 samples of aged 60 and above in seven rural communes of Udham Singh Nagar. Findings reveal that majority of the elderly, both male and female, are unhealthy. The most common health problems aged people face include eye sight, joint pains, weakness, digestion complaints and others. More health problems were reported by female compared to male.

KEY WORDS: Ageing, Physiological functions, Elderly, Village ecosystem, Health problems

- HOW TO CITE THIS PAPER : Rani, Sandhya and Sharma, Promila (2015). Elderly at the edge of risk in the village ecosystem. Asian J. Home Sci., 10 (2) : 337-341. 